\title{
STAT3 activation in monocytes accelerates liver cancer progression
}

Wen-Yong $\mathrm{Wu}^{1}$, Jun $\mathrm{Li}^{\mathrm{i}^{*}}$, Zheng-Sheng $\mathrm{Wu}^{3}$, Chang-Le Zhang ${ }^{1}$ and Xiang-Ling Meng ${ }^{1}$

\begin{abstract}
Background: Signal transducer and activator of transcription 3 (STAT3) is an important transcription factor ubiquitously expressed in different cell types. STAT3 plays an essential role in cell survival, proliferation, and differentiation. Aberrantly hyper-activated STAT3 signaling in cancer cells and in the tumor microenvironment has been detected in a wide variety of human cancers and is considered an important factor for cancer initiation, development, and progression. However, the role of STAT3 activation in monocytes in the development of HCC has not been well understood.

Methods: Immunohistochemical analysis of phosphorylated STAT3 was performed on tissue microarray from HCC patients. Using a co-culture system in vivo, HCC cell growth was determined by the MTT assay. In vivo experiments were conducted with mice given diethylinitrosamine (DEN), which induces HCC was used to investigate the role of STAT3 expression in monocytes on tumor growth. Real-time PCR was used to determine the expression of cell proliferation and cell arrest associated genes in the tumor and nontumor tissue from liver.

Results: Phosphorylated STAT3 was found in human hepatocellular carcinoma tissue samples and was expressed in tumor cells and also in monocytes. Phosphorylated STAT3 expression in monocyte was significantly correlated to advanced clinical stage of HCC and a poor prognosis. Using a co-culture system in vivo, monocytes promoted HCC cell growth via the IL-6/STAT3 signaling pathway. The STAT3 inhibitor, NSC 74859, significantly suppressed tumor growth in vivo in mice with diethylinitrosamine (DEN)-induced HCC. In this animal model, blockade of STAT3 with NSC 74859 induced tumor cell apoptosis, while inhibiting both tumor cells and monocytes proliferation.

Furthermore, NSC 74859 treatment suppressed cancer associated inflammation in DEN-induce HCC.

Conclusion: Our data suggest constitutively activated STAT3 monocytes promote liver tumorigenesis in clinical patients and animal experiments. Thus, STAT3 in tumor infiltrating inflammatory cells may an attractive target for liver cancer therapy.
\end{abstract}

Keywords: STAT3, Liver cancer, Inflammation

\section{Background}

A causal link between chronic inflammation and the development of cancer has long been recognized from clinical and animal investigations and has become an issue of high interest in recent years [1]. Although it is well accepted that chronic inflammation can affect all phases of carcinogenesis, from the initial cancer formation by inducing genetic alteration, to the subsequent cancer formation by establishing an inflammatory environment that allows

\footnotetext{
* Correspondence: aydlj@sina.cn

${ }^{2}$ School of Pharmacy, Anhui Medical University, 81 Meishan Road, Hefei,

Anhui 230032, People's Republic of China Full list of author information is available at the end of the article
}

tumors to grow, metastasize and escape the host antitumor immune response [1,2], the exact mechanisms of inflammation favoring carcinogenesis are largely currently unknown. The interplay between chronic inflammation and cancer is very complex. Previous reviews have already demonstrate this interesting issue in detail $[1,2]$. Briefly, chronic inflammation and incomplete repair can hasten the oncogenic processes by directly promoting genetic instability and favoring the induction of gene mutation. It is believed abundant reactive oxygen (ROS) produced by inflammatory cells can induce DNA damage, mutations and genetic instability. Secondly, many well known oncogenic genes including RAS, RET, BRAF and MYC appear
C Biomed Central 
to play a role in inflammation as well [3]. These oncogenes turn on the inflammatory pathway within a cell, activate inflammation outside the cell to recruit inflammatory cells leading to an immuno-suppressive tumor microenvironment $[2,4,5]$. Lastly, many transcription factors such as $\mathrm{NF}-\kappa \mathrm{B}, \mathrm{STAT} 3$ and the adaptor protein MyD88, which are all key to the innate inflammatory response, are also essential in certain kinds of cancers [6-9].

Constitutively activated IL-6/STAT3 signaling has been detected in a wide variety of human cancers including liver cancer and is considered an important factor for cancer initiation, development, and progression [7,10-12]. Hepatocellular carcinoma (HCC) is the most common primary malignancy in liver and the third leading cause of cancer deaths worldwide, with few effective therapeutic options for this severe disease [13-15]. Most HCC appears in cirrhotic livers after years of chronic liver inflammation caused by hepatitis viral infection, alcoholic and non-alcoholic steatohepatitis $[14,16]$. Various factors can active hepatic STAT3 signaling such as inflammatory cytokines, growth factors, hormones, and hepatitis viral proteins [17]. Several cytokines (such as IL-6, IL-6 family cytokines and IL-22) that activate STAT3 in hepatocytes have been shown to promote HCC cell growth in vivo and in vivo $[18,19]$. Recently, Park et al. reported that localized production of IL-22 in the liver promotes hepatocyte survival and proliferation, thereby accelerating the HCC development after DEN challenge [20]. Moreover, emerging evidence suggests that the cytokines downstream of STAT3 play an important role in the development of liver cancer [21-23]. Blockage of STAT3 may have therapeutic potential in preventing and treating liver cancer [24-26]. Our previous study on HCC specimens suggests an oncogenic role of STAT3 in liver cancer. In the previous study tumor expression of STAT3 was correlated with disease progression and poor survival rates [27]. In the present study we further investigate whether monocyte expression of STAT3 in the tumor microenvironment could promote tumor growth and whether the STAT3 inhibitor, NSC 74859, can prevent diethylinitrosamine (DEN)-induced HCC by suppressing STAT3 activation and its associated inflammation.

\section{Methods}

\section{Cancer specimens}

A total of $138 \mathrm{HCC}$ patients were enrolled in this study with an informed patient consent following the human study protocol approved by the Anhui Medical University Ethics Committee. Formalin-fixed and paraffin-embedded $\mathrm{HCC}$ and normal liver specimens were obtained from the Department of Pathology within the First Affiliated Hospital of Anhui Medical University, P.R. China. All HCC samples were collected from patients with varying grades and stages of cancer. Two independent pathologists evaluated blinded tumors samples used in this study. All the hematoxylin and eosin-stained sections from each paraffinembedded, formalin-fixed block were reviewed to identify target areas.

\section{Tissue microarrays (TMA) construction}

Paraffin-embedded tumor specimens were obtained from an archive of the Department of Pathology within the First Affiliated Hospital of Anhui Medical University, P.R. China. TMAs were constructed as previously described [27]. Three to five representative $1 \mathrm{~mm}$ cores were obtained from each case and inserted in a grid pattern into a recipient paraffin block (Hengtai Instruments Inc., Liaoning, P.R. China).

\section{Immunohistochemistry staining}

TMA sections of HCC were stained through immunohis-

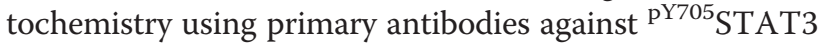
(Cell Signaling Technology, Danvers, MA, USA). The frequency of $\mathrm{p}^{\mathrm{Y} 705} \mathrm{STAT} 3$-positive cells was measured by counting the total number of cells and the number of positively stained cells. More than 25\% nuclear staining was classified as positive.

For cell proliferation Ki67 staining, the sections were stained in accordance with routine immunohistochemistry procedures and visulaized with the $\mathrm{ABC}$ kit (Vector Laboratories, Burlingame, CA, USA). Biotinylated rat antimice Ki67 antibody at 1:100 dilution was used. Hepatocyte or tumor cell apoptosis was detected by using an Apoptag Apoptosis Detection Kit (Chemicon International, Temecula, CA, USA).

\section{Co-culture of monocytes and HCC cells}

The HCC cell lines HepG2 and Huh-7 were obtained from the Shanghai cell bank, Chinese Academy of Sciences, Shanghai, China. These two cell lines were maintained in Dulbecco's Modified Eagle's Medium (DMEM). Both types of medium were supplemented with $10 \%$ fetal bovine serum.

PBMCs from health subjects were freshly isolated by gradient centrifugation from discarded leukocyte filters obtained during platelet collection from healthy adults at the First Affiliated Hospital of Anhui Medical University. Monocytes were isolated by negative selection using Dynal Monocyte Negative Isolation Kit (Invitrogen) according to the manufacturer's instructions. All in vivo experiments were performed in Ultra Low Attachment Plates (Corning) to prevent monocyte activation by adhesion to the plastic plate. In co-culture experiments, freshly isolated monocytes $\left(5 \times 10^{6}\right)$ were added to the inserts separated by $0.4-$ $\mu \mathrm{m}$ membrane (Costar; Corning) from HCC cells. For the cell proliferation analysis, HCC cell line HepG2 or Huh-7 were co-cultured with or without moncytes for $48 \mathrm{~h}$ and the MTT assay was performed as described below. 


\section{3-(4, 5-Dimethylthiazol-2-yl)-2, 5-diphenyltetrazolium bromide (MTT) assay}

The MTT assay is based on the conversion of the yellow tetrazolium salt MTT to purple formazan crystals by metabolically active cells. The MTT assay provides a quantitative determination of viable cells. Cells $\left(1 \times 10^{4}\right)$ were seeded in 96-well microplates in complete culture medium in the absence or presence of anti-IL-6 antibody or NSC 74859 as indicated. After $72 \mathrm{~h}$ of culturing, the number of viable cells was measured by adding $100 \mu \mathrm{l} /$ well of $2 \mathrm{mg} / \mathrm{ml}$ MTT solution. The medium was removed $2 \mathrm{~h}$ later and the formazan crystals were dissolved by adding $100 \mu \mathrm{l}$ dimethylsulfoxide per well. The absorbance was read at $590 \mathrm{~nm}$ with an enzyme-linked immunosorbent assay reader. Each treatment point was performed with an $\mathrm{n}=6$.

\section{Mice and diethylnitrosamine (DEN)-induced liver cancer model}

All experiments with mice were approved by Anhui Medical University Animal Care and Use Committee. C57BL/6 mice were obtained from Animal Center of Anhui Medical University. Mice were kept in pathogen-free conditions with room temperature of (23 $\pm 2 \mathrm{C})$, humidity (55-60\%), and light conditions (12 h light/dark cycle).

The DEN-induced liver tumor model in mice was established as described previously [28,29]. Briefly, 15-day-old B6 mice were injected with $5 \mu \mathrm{g} / \mathrm{g}$ DEN (Sigma, St. Louis, MO). Six months after the injection series with normal chow, all the mice were randomly separated into two groups; the NSC 74859 group or vehicle only group. Mice were then injected intraperitoneally with $5 \mathrm{mg} / \mathrm{kg}$ NSC 74859 twice per week for 3 months prior to sacrifice at 9 months after DEN injection. Livers were removed and the tumor numbers and sizes were analyzed. Histological sections were taken including larger tumor nodules that were fixed in $10 \%$ formalin. Hematoxylin-eosin (H\&E) staining was performed using standard protocols. The liver tumor tissues and nontumor tissues were carefully separated and frozen in liquid nitrogen for subsequently real-time PCR determination.

For liver tumor analysis, the whole liver was carefully removed from the euthanized animal, washed and placed in cold PBS. The numbers of surface liver tumor nodules were counted for all liver lobes in a blinded fashion. Liver nodules typically presented as basophilic foci with crowded nuclei and were classified as atypical foci (HCC) or hepatocellular adenomas.

\section{Real-time PCR}

Real-time PCR was used to determine the expression of cell proliferation and cell arrest associated genes in the tumor and nontumor tissues from liver samples. Total RNA was purified from approximately $30 \mathrm{mg}$ of liver tumor or nontumor samples according to the manufacturer instruction (Qiagen). $1 \mu \mathrm{g}$ of mRNA was reversetranscribed to cDNA using a High Capacity cDNA Reverse Transcription kit (Invitrogen). cDNA templates were diluted 1:5 and amplified using real-time PCR through the iTaq SYBR Green Supermix (Bio-Rad, Hercules $\mathrm{CA}$ ). An initial denaturation at $95^{\circ} \mathrm{C}$ for 3 min was followed with PCR cycling: $95^{\circ} \mathrm{C}(15 \mathrm{sec})$, and $58^{\circ} \mathrm{C}(30$ sec) for 40 cycles. Relative mRNA levels were calculated by means of $2^{-\Delta \Delta C t}(\Delta \Delta C t=$ difference of crossing points of test samples and respective control samples as extracted from amplification curves by the LightCycler software) after normalization to $18 \mathrm{~S}$ rRNA expression, which was used as an internal standard. Fold inductions of analyzed mRNA expression were normalized on $18 \mathrm{~S}$ rRNA expression. PCR was performed with $12.5 \mu$ SYBR Master Mixture and the following primers in Table 1.

\section{Statistical analysis}

All statistical analyses were performed using SPSS software system for Windows (version 13.0; SPSS, Chicago, IL, USA). Differences between groups were compared using Pearson's chi-square test for qualitative variables and Student's $t$-test for continuous variables. KaplanMeier curves were constructed to determine patient relapse-free survival (RFS) and overall survival (OS) rates. The statistical differences in survival among subgroups were compared using the log-rank test. Data of HCC mice model were expressed as means $\pm \mathrm{SE}(\mathrm{N}=4-8$ in each group). To compare values obtained from three or more groups, 1-factor analysis of variance (ANOVA) was used, followed by Tukey's post hoc test. $P<0.05$ was considered statistically significant. The correlations between variables were assessed by the Spearman rank order test. Statistical significance was taken at the $P<0.05$ level.

\section{Results}

Phosphorylated STAT3 in hepatocellular carcinoma tissue is not only expressed on tumor cells, but also on monocytes

Previous study have shown that STAT3 and pSTAT3 expression is dramatically increased in HCC tissues when compared with normal liver samples [22]. To further

\section{Table 1 Primer sequences for real-time PCR}

\begin{tabular}{|c|c|c|}
\hline genes & Forward primer $\left(5^{\prime} . . .3^{\prime}\right)$ & Reverse primer $\left(5^{\prime} \ldots 3^{\prime}\right)$ \\
\hline TNF- $\alpha$ & AAGCCTGTAGCCCACGTCGTA & AGGTACAACCCATCGGCTGG \\
\hline IL-1 $\beta$ & AAAAAAGCCTCGTGCTGTCG & GTCGTTGCTTGGTTCTCCTTG \\
\hline IL-6 & TCCATCCAGTTGCCTTCTTG & TTCCACGATTTCCCAGAGAAC \\
\hline MCP-1 & TCAGCCAGATGCAGTTAACGC & TCTGGACCCATTCCTTCTTGG \\
\hline IFN- $\gamma$ & GCCCTCTCTGGCTGTTACTG & CTGATGGCCTGGTTGTCTIT \\
\hline $18 \mathrm{~s}$ & GTAACCCGTTGAACCCCATT & CCATCCAATCGGTAGTAGCG \\
\hline
\end{tabular}


investigate which cell types, in addition to tumor cells, were responsible for pSTAT3 activation and the STAT3 signaling and whether this signaling pathway was correlated with the prognosis of HCC patients, we initially used immunohistochemistry to analyze pSTAT3 expression in HCC tissues and its association with patient's clinicopathological parameters (Table 2). Positive pSTAT3 staining in monocytes and overall survival was evaluated using Kaplan-Meier survival curves and the log-rank test (Figure 1b). After reviewing the TMA slides of HCC, we found 113 out of 138 HCC cases had the inflammation cells infiltration. Among the 113 patients studied, 92 patients were classified as HBsAg positive and 101 patients were classified as cirrhosis patients. In the non-peritumoral area in tumors from these patients, the inflammatory cell infiltration was generally dense, as seen in the cirrhotic stroma, and several pSTAT3 positive monocytes were detected (not taken into account in the evaluation). To clarify the interaction between the monocytes and tumor cells in the tumor microenvironment, pSTAT3 expression was investigated in the limited areas

Table 2 Correlation of pSTAT3 expression in moncytes with clinicopathological parameters from HCC patients ( $n=113$ )

\begin{tabular}{cclc}
\hline Parameter & $\boldsymbol{n}$ & pSTAT3 positive expression, $\boldsymbol{n}$ (\%) & $\boldsymbol{p}$ value \\
\hline Age (years) & & & \\
\hline$\leq 55$ & 67 & $45(67.2)$ & 0.067 \\
\hline$>55$ & 46 & $23(50.0)$ & \\
\hline Gender & & & 0.627 \\
\hline Male & 93 & $55(59.1)$ & \\
\hline Female & 20 & $13(65.0)$ & \\
\hline Cirrhosis & & & \\
\hline Yes & 101 & $63(62.4)$ & \\
\hline No & 12 & $5(41.7)$ & \\
\hline HBsAg & & & 0.193 \\
\hline Yes & 92 & $58(63.0)$ & \\
\hline No & 21 & $10(47.6)$ & \\
\hline Tumor size (cm) & & & 0.336 \\
\hline$<5$ & 32 & $17(53.1)$ & \\
\hline$\geq 5$ & 81 & $51(63.0)$ & \\
\hline Grade & & & \\
\hline I & 4 & $2(50.0)$ & \\
\hline II & 107 & $64(59.8)$ & \\
\hline III & 2 & $2(100.0)$ & \\
\hline Stage & & & \\
\hline I-II & 86 & $47(54.7)$ & \\
\hline III-IV & 27 & $21(77.8)$ & \\
\hline$<50 \%$ & 45 & $24(53.3)$ & \\
\hline$\geq 50 \%$ & 68 & $44(64.7)$ & \\
\hline
\end{tabular}

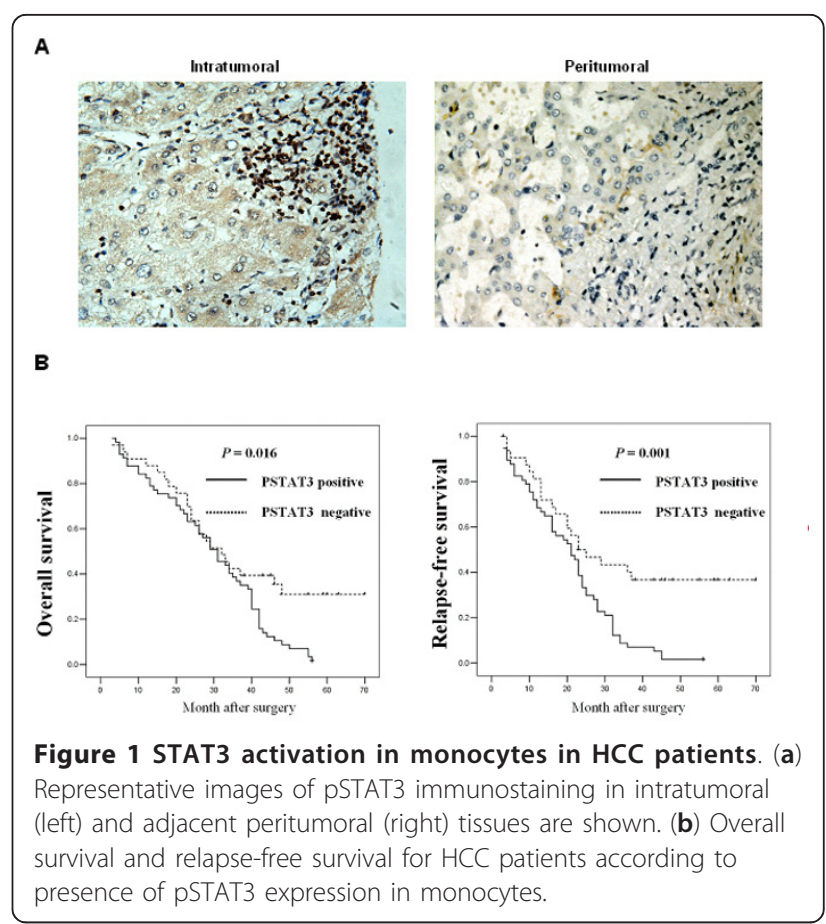

of the peritumoral and the intratumoral area. As shown in Table 3, a statistically significant difference of pSTAT3 was observed in tumor cells $(54.3 \%)$ and monocytes (60.2\%) when compared with adjacent non-tumorous tissue. As shown in Table 4, a statistically significant correlation was seen between pSTAT3 expression in tumor cells and its adjacent pSTAT3 positive monocytes by Spearman correlation analysis $(P<0.001, \mathrm{rs}=0.440)$. For the non-tumoral liver tissue (tissue away from the peritumoral and intratumoral area), the pSTAT3 expression was weak or scarce except for the inflammatory foci area. These data are summarized in Tables 2, 3 and 4. Interestingly, expression of pSTAT3 in monocytes was increased in intratumoral tissues compred to adjacent peritumoral tissues (Figure 1a). Monocyte expression of pSTAT3 was significantly correlated to higher clinical stages of $\mathrm{HCC}$ $(P=0.032$, Table 1$)$. Next, we further identify the correlation of pSTAT3 expression in monocytes with the prognosis of HCC inpatients. As shown in Figure 1b, HCC patients with enhanced pSTAT3 expression in monocytes had a significantly worse OS and RFS after curative

Table $\mathbf{3}$ Expression of pSTAT3 in HCC and adjacent
non-tumour tissue specimens
\begin{tabular}{llllll}
\hline Group & $\boldsymbol{n}$ & \multicolumn{4}{l}{ Positive expression of pSTAT3 protein, $\boldsymbol{n}$} \\
\cline { 2 - 6 } & & tumor/liver cells & $\boldsymbol{n}$ & monocytes \\
\hline HCC & 138 & $75(54.3)^{*}$ & 113 & $68(60.2)^{*}$ \\
\hline Non-tumorous & 110 & $35(31.8)$ & 110 & $27(24.5)$ \\
\hline${ }^{*} P<0.001$ & &
\end{tabular}


Table 4 Correlation analysis of pSTAT3 expression between in tumor cell and monocyte in HCC

\begin{tabular}{lll}
\hline Monocyte expression of pSTAT3 & \multicolumn{2}{l}{ Tumor cell expression of pSTAT3 } \\
\cline { 2 - 3 } & Negative & Positive \\
\hline Negative & $87(68.0)$ & $41(32.0)$ \\
\hline Positive & $38(40.0)$ & $57(60.0)$ \\
\hline$* P<0.001, r_{s}=0.440$
\end{tabular}

$* P<0.001, \mathrm{r}_{\mathrm{s}}=0.440$

resection than those without pSTAT3 expression $(P=$ 0.016 and 0.001 , respectively).

\section{Monocytes promote HCC cells growth via IL-6/STAT3 pathway}

To further analyze the underlying mechanism of the poor prognosis in $\mathrm{HCC}$ with increased expression of monocyte STAT3, we cultured HCC cell lines HepG2 or Huh-7 alone, or co-cultured these cells using transwell chambers with HCC cells in the presence of peripheral bloodderived monocytes. As shown in Figure 2, cell proliferation of HepG2 or Huh-7 was much higher in co-cultures of both cell types for 24 hrs when compared with single culture of HCC cells. Pretreated with an IL-6 antibody or STAT3 inhibitor significantly suppressed HCC cells growth. Cell proliferation was comparable between HCC cells only and tumor cells treated with or without IL-6 antibody or STAT3 inhibitor. These in vivo data clearly show that activated STAT3 in monocytes can promote cancer cells growth in a paracrine dependent manner.

\section{Inhibition of STAT3 with NSC 74859 results in tumor} regression in DEN-induced HCC mouse model

Previous studies have shown that STAT3 inhibitors can suppress tumor cell growth in vivo and tumor growth in a tumor xenograft mouse model [22]. Here, using the traditional DEN-induced HCC model, we investigated the effects of the STAT3 inhibitor, NSC 74859, on HCC development. Both the control and the STAT3 inhibitor treated mice (8 mice per group) were injected with DEN at day 15. Both NSC 74859 and the vehicle alone were injected intraperitoneally at $5 \mathrm{mg} / \mathrm{kg}$ twice per week for 3 months prior to sacrificing the mice at 9 months after DEN injection. The numbers of surface liver tumor nodules from all liver lobes were enumerated and the sizes of the tumor nodules were also calculated. As illustrated in Figure 3, injection of NSC 74859 inhibited tumor development in the DEN-induced tumor model. The tumor size and number were significantly smaller in NSC 74859 treated mice compared to wild-type mice after injection of $20 \mu \mathrm{g} / \mathrm{g}$ of DEN.

Histological analysis (Figure 3) shows that liver tumors from both groups had a moderate degree of differentiation with an increased nuclear-to-cytoplasmic index, enlarged and hyperchromatic nuclei and expansive growth. In the

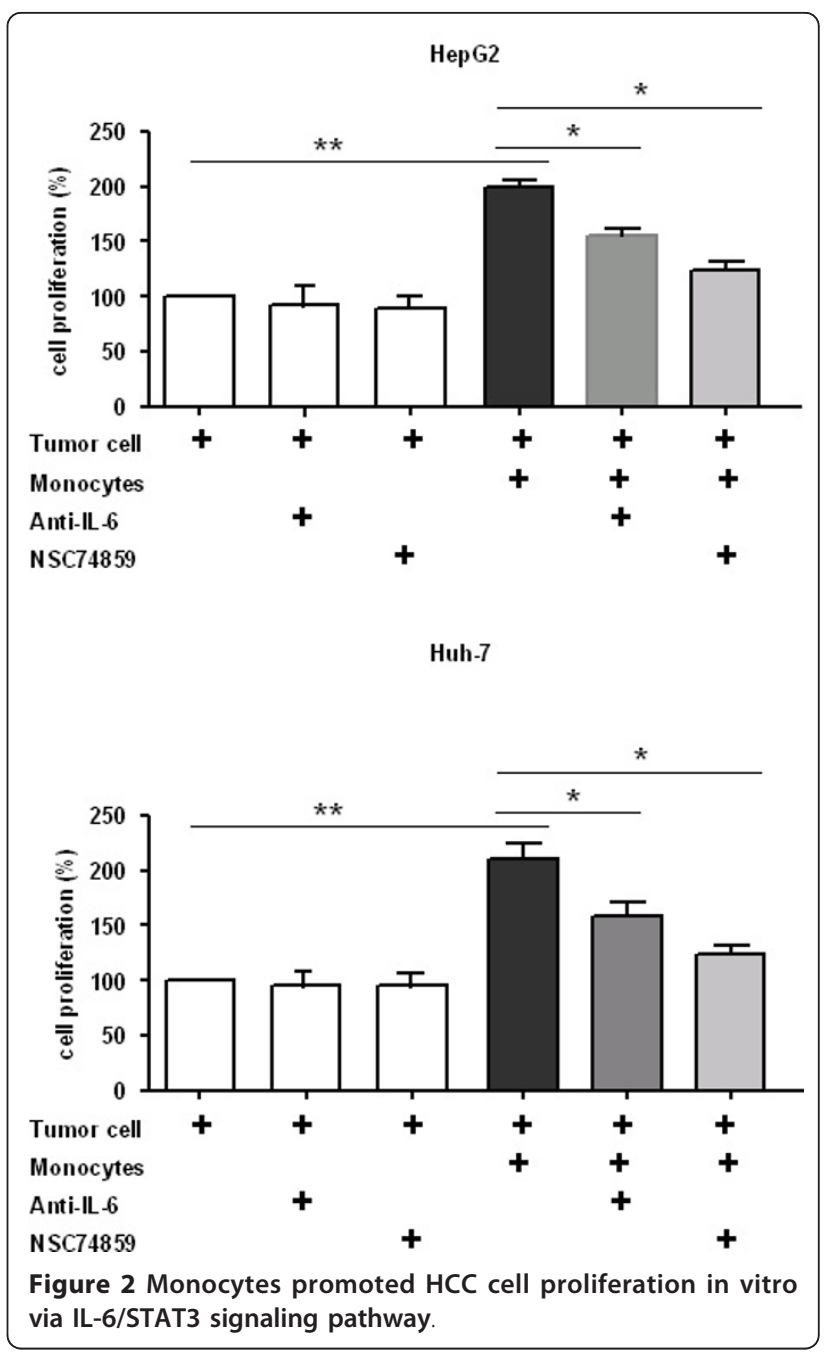

area of the tumor tissues, the normal liver architecuture, such as bile duct and portal tract formation, was lost. Consistent with the results in Figure 3a, the tumor size was much smaller after NSC 74859 treatment. These data clearly demonstrate the anti-tumor capacity of NSC 74859 in DEN-induce HCC development. Immunohistochemical staining analysis also shows stronger pSTAT3 expression in both tumor and inflammatory cells compared to the vehicle control treatment mice, while NSC74859 markedly decreased pSTAT3 expression (Figure 3). Hematoxylin and eosin staining indicate a large inflammatory cell infiltration in DEN-treated mice, compared to vehicle control mice. Inflammation reduced in the adjacent area to tumor tissue after NSC 74859 therapy (Figure 3).

Blockade of STAT3 with NSC 74859 induced tumor cell apoptosis, while inhibited both tumor cells and monocytes proliferation in DEN-induced HCC mouse model

To explore the possible mechanisms underlying the anti-tumor effects of the STAT3 inhibitor in this HCC 


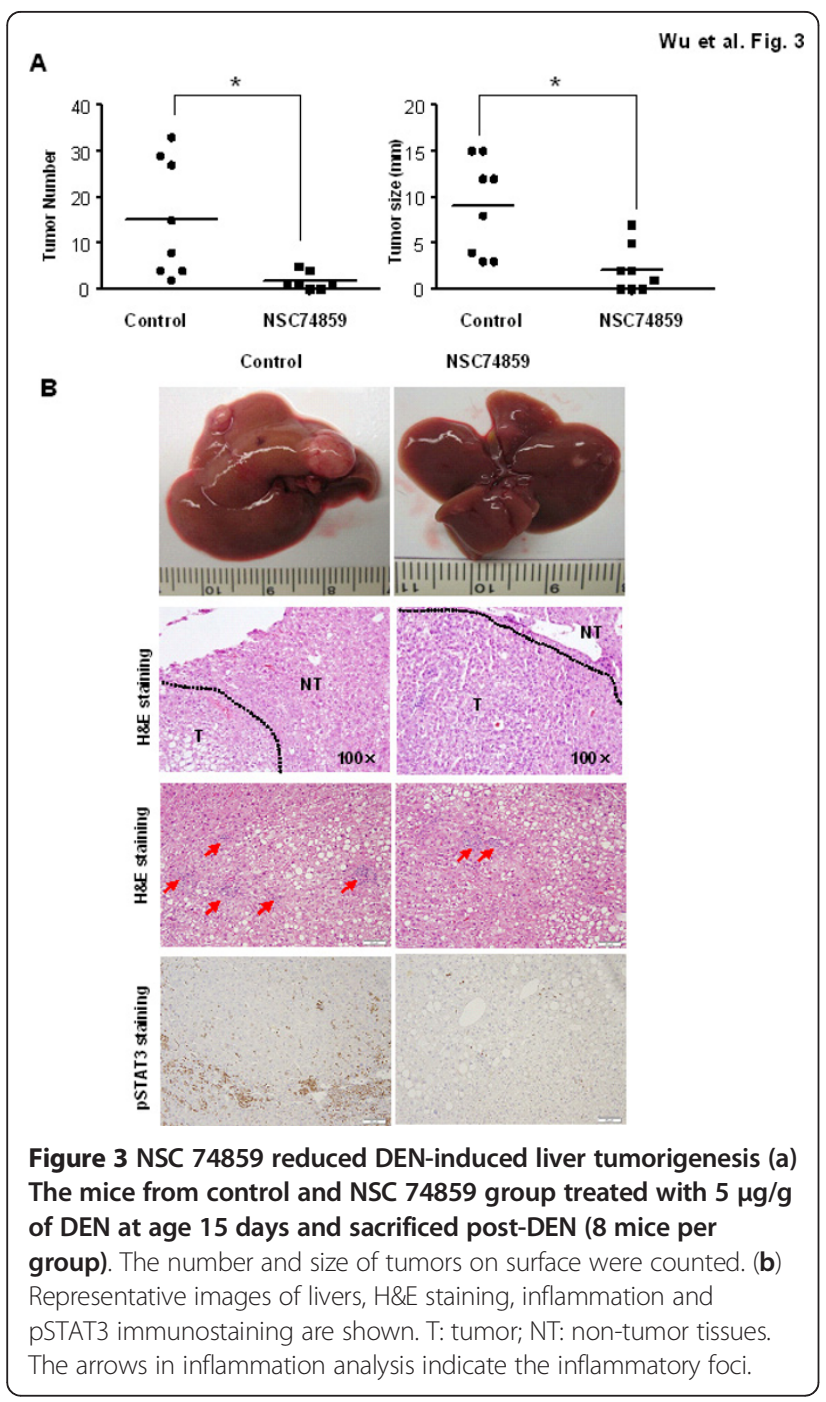

model, we performed TUNEL and Ki67 staining in liver tumor tissue after DEN exposure in both groups. As shown in Figure 4, administration of NSC 74859 led to more apoptotic tumor cells and less $\mathrm{Ki} 67^{+}$tumor cells. Moreover, NSC 74859 also reduced the cancer-associated inflammatory cell proliferation.

Constitutively activated STAT3 promotes tumorigenesis through the upregulation of cell cyclin related gene [12,30-32]. Therefore, we compared the cell cyclin related gene expression (Cyclin B1, Cyclin D, Cyclin E and p21) between the NSC 74859 treatment and control groups through real-time PCR. The expression of Cyclin B1, Cyclin D and Cyclin E in NSC 74859 treated mice were low compared with the untreated mice in both tumor tissue and non-tumor tissue, as shown in Figure 5 , which was correlated with the reduced proliferation in the NSC 74859 treated group. In contrast, the level of p21 was higher in NSC 74859 group compared with the untreated controls.

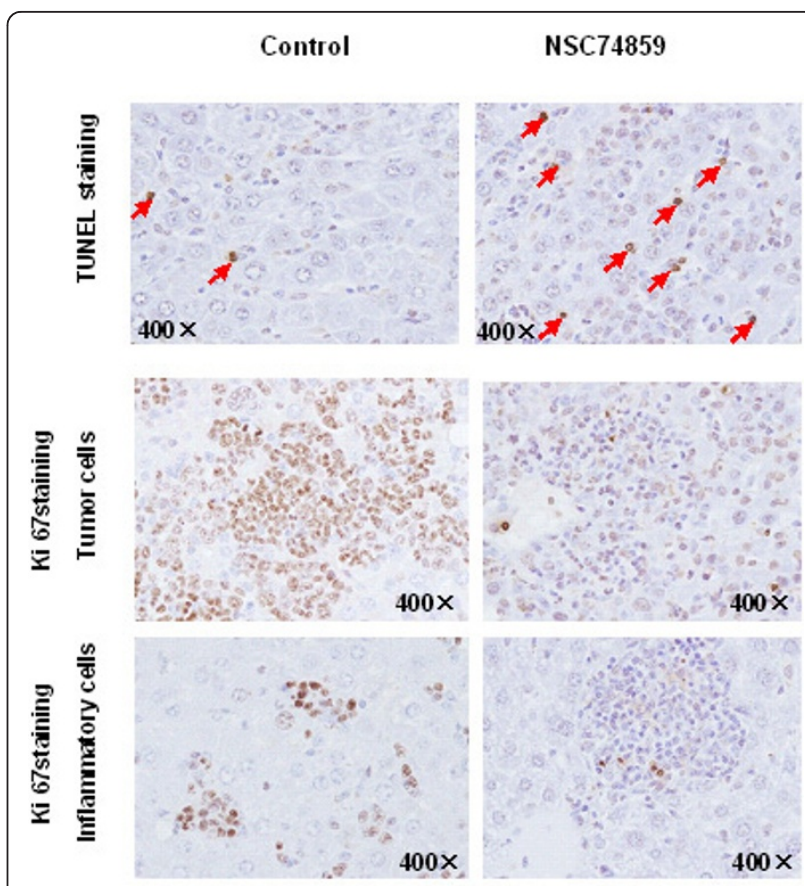

Figure 4 NSC 74859 promoted tumor cell apoptosis while inhibited tumor cell and monocytes proliferation Representative images of TUNEL staining and Ki67 immunostaining are shown.

NSC 74859 suppressed cancer associated inflammation in DEN-induce HCC

Since a causal relationship between chronic injury and inflammation and liver carcinogenesis in the majority of HCC patients is well established, we wondered whether the STAT3 inhibitor can also affect liver inflammation in the DEN-induced HCC model. To test this possibility, the mRNA expression of several pro-inflammatory

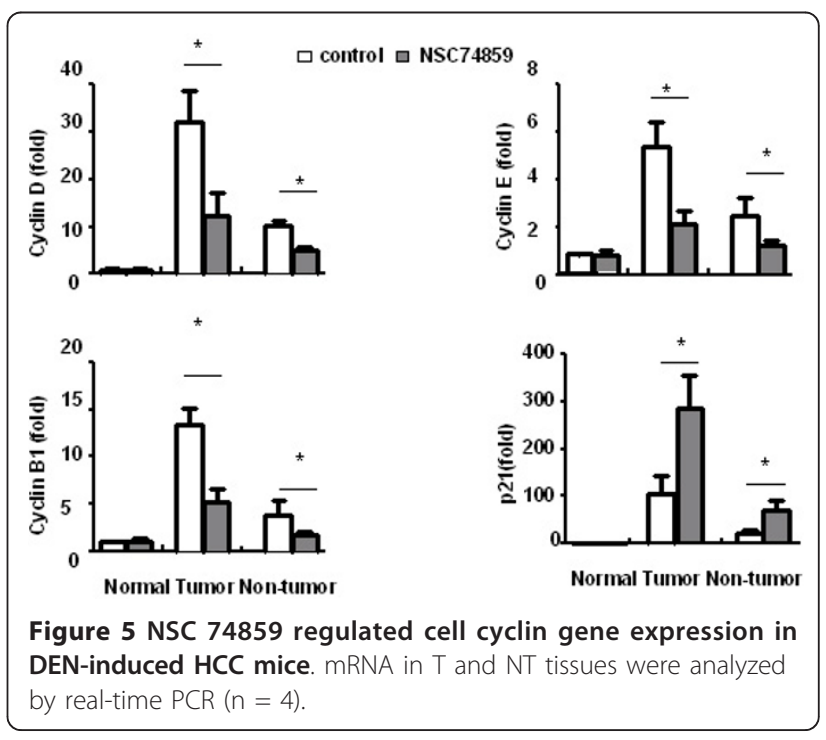


cytokines (IL-6 and TNF- $\alpha$ ) and inflammatory markers of macrophages (F4/80) and monocytes (CCR2) were examined using real-time PCR in mice with or without NSC 74859 treatment. Interestingly, as illustrated in Figure 6, both tumor and non tumor tissue after STAT3 inhibitor administration displayed less expression of inflammatory cell marker and cytokines compared with those in untreated tissue. Those data indicated the STAT3 inhibitor also can reduce inflammation after DEN challenge.

\section{Discussion}

Although transcription factors such as NF- $\kappa \mathrm{B}$ and STAT3, are key molecules implicated in cancer-related inflammation [21-23,33-36], the current study provides several novel findings demonstrating the importance of monocytes STAT3 activation in facilitating HCC progress in human patients and in an animal model. First, a negative correlation was observed between STAT3 activation in monocytes and overall survival in human $\mathrm{HCC}$ patients. Second, in co-culture experiemtns with monocytes and tumor cells, monocytes enhance HCC cell proliferation, which was dependent on IL-6/STAT3 signaling pathway. And finally, STAT3 inhibitor treatment in DEN-induced HCC animal not only reduced tumor growth but also ameliorated cancer associated inflammation via inhibiting inflammatory cell STAT3 activation. These finding indicates that monocyte-dervied STAT3 is a possible new therapeutic target for HCC.

The presence of inflammatory cells including monocytes in the tumor microenvironment has been widely reported. The function of these cancer associated inflammatory cells is complicated and generally viewed as both beneficial as anti-tumorogenic and tumor promoting in regards of the immune response. In the present study, we observed monocytes infiltrating the peritumoral and intratumoral area of HCC and the associated STAT3

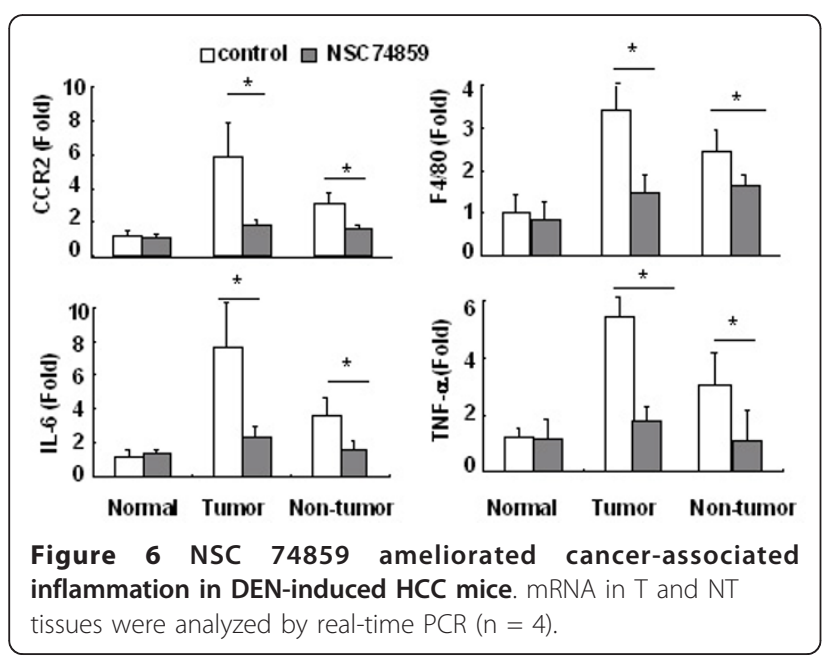

activation, which was statistically significant and associated with poor prognosis in these cells is prominent. At present, the underlying mechanisms for these inflammatory cells are not well known. Previous studies indicate that the immunosuppressive response, angiogenic factors and tumor-promoting chemokines induced by infiltrating inflammatory cells contribute to tumor growth and metastasis [10]. Recently, IL-17 and IL-21, synthesized by immune cells has been shown to promote tumor development in inflammation-associated cancers $[37,38]$

Our results, along with the study in other different types of cancer [7,10-12], indicate the existence of an association between STAT3 activation in monocytes and poor prognosis. (Figure 1). This observation in clinical setting suggests that tumor-infiltrating monocytes STAT3 expression may have a protumoral function. Although most of patients in our study have the history of HBV infection, it is very difficult to clarify the relationship between natural history of the HBV infection and STAT3 activation. HCC is the very late stage of severe liver disease and survival time of the patients is limited. One interesting finding showed that STAT3 expression and phosphorylation was not altered in HCV-fibrosis patients and alcoholic cirrhosis, while STAT3-DNA binding was markedly suppressed in all alcoholic and most HCV fibrosis patients when compared with that in normal healthy livers[39,40]. Elucidating the roles STAT3 in HBV infection and HBV inducing neoplastic transformation will shed light on the molecular basis of liver cancer and may suggest therapeutic strategies for this severe disease.

IL-6 is a multifunctional cytokine which is known to affect proliferation, apoptosis and angiogenesis in cancer [41]. In liver disease, clinical data also indicate that serum IL-6 concentrations are elevated in patients with chronic liver inflammation, and steatohepatitis as well as in patients with HCC [42]. Notably, men are about three to five times more likely to develop HCC than women [43]. Similar gender disparity was also observed in a murine model of HCC induced by diethylnitrosamine (DEN). It is believed that higher serum levels of IL- 6 in male mice contribute to the increased susceptibility to DEN-induced liver cancer in these mice compared with female mice [19]. Since IL-6 can strongly activate the STAT3 signaling pathway, it is reasonable to expect STAT3 also plays a critical role in HCC development. Indeed, a previous study has already reported constitutively activated STAT3 in human liver tumor tissues [22]. Consistent with this study, we also found STAT3 activation in tumor cell. Moreover, we observed STAT3 activation in infiltrated monocytes adjacent to tumor tissue (Figure 1a). Activated STAT3 in monocytes are positively correlted with a poor prognosis (Figure 1b). Previous study showed that, strong STAT3 immunostaining was observed in the cytoplasm of HCC tissues, while pY705STAT3 immunostaining was observed 
in the nucleus [22]. Additionally, blockage of STAT3 using chemical inhibitors or siRNA induced liver cancer cell apoptosis and cell cycle arrest in vivo, and inhibited growth of transplanted liver cancer cells in vivo [22]. In this study, we observed that altered p-STAT3 expression was significantly and positively correlated with the histological grading and intratumor microvessel density in HCC. Interestingly, recent studies suggest that STAT3 activation is also implicated in HCV- and obesity-mediated hepatocarcinogenesis [35,36]. Another important evidence for the role of STAT3 in liver cancer development is that constitutively activated STAT3 is detected in cancer stem cells from HCC and likely contributes to liver cancer stem cell proliferation and survival [44]. Collectively, Activation of STAT3 in cancer cells plays an important role in liver tumorigenesis.

The oncogenic role of constitutively activated STAT3 is driven through the up-regulation of cell survival proteins (Bcl-xl, Bcl-2), cell cycle regulators (c-Myc, cyclin D) [12,30-32], anti-oxidant genes (Mn-SOD, ferritin, catalse), and tissue repair genes $(\operatorname{Reg} \beta, \operatorname{Reg} \gamma, \operatorname{Tff} 3)[31,45,46]$. Our study also showed that STAT3 inhibitor treatment downregulated cell proliferation-related gene expression. Recently, a key novel molecule, sphingosine-1-phosphate receptor-1 (S1PR1) that is induced by STAT3, has been discovered to play an important role in inducing persistent STAT3 activation in tumor cells and in the tumor microenvironment [47].

Besides promoting tumor cell proliferation and inhibiting cell apoptosis $[31,48,49]$, the activation of STAT3 in cancer cell has also shown to increase the capacity of tumor to evade the immune system, by inhibiting the maturation of dendritic cells and suppressing the immune response $[7,50]$. Overexpression of STAT3 in tumor cells can recruit tumor-infiltrating hematopoietic cells by producing chemotactic factors, resulting in infiltrating inflammatory immune cells and subsequently STAT3 activation in immune cells. The interplay of STAT3 in cancer cells and immune cells in tumor microenvironment is very complex and remains elusive. Previous studies show that the persistent activation of STAT3 in immune/inflammatory cells is also very important in the control of tumor promotion and progression through tumor-promoting inflammation and suppressing anti-tumor immunity[51-53]. Our study demonstrates that in vivo monocytes can promote liver cancer cell proliferation via IL-6/STAT3 signaling pathway (Figure 2). This is direct evidence to demonstrate STAT3 in monocytes can broadly and profoundly affect tumor growth via stimulation of tumor cell survival and proliferation. In vivo, STAT3 inhibitors can also decrease cancerassociated inflammation, suggesting that targeting leukocyte STAT3 in the tumor microenvironment may be a therapeutic option that will be applicable in the future. However, these results are in contrast to a previous report
[54]. In this report, the authors indicate that the deletion of STAT3 in myeloid cells, including leukocytes, enhances inflammation in concanavalin A-induced hepatitis. These results suggest that STAT3 inhibition in immune cells leads to enhanced inflammation. These conflicting observations indicate the complexity of molecular mechanisms underlying liver inflammation and cancer. Decreased tumor-associated inflammation induced by STAT3 inhibitor may be a secondary response after the inhibition of STAT3 in tumor cells. Future studies will determine why STAT3 inhibitors decrease tumor-associated inflammation while enhancing necrotic-associated inflammation.

\section{Conclusions}

Our study clearly suggests constitutively activated STAT3 monocytes promoting liver tumorigenesis in clinical patients and animal experiments. STAT3 in tumor infiltrating monocytes also is an attractive target for cancer therapy.

\section{Acknowledgements}

This work was supported in part by a grant from the National Natural Science Foundation of China (\#81072686), Key University Natural Science Foundation of Anhui (\#KJ2011z211), Anhui Medical University (\#2010xkj058). We thank Dr. Hua Wang and Dr. David J. Blake for critical reading of this manuscript.

\section{Author details}

'Department of General Surgery, First Affiliated Hospital of Anhui Medical University, Anhui, Hefei, People's Republic of China. ${ }^{2}$ School of Pharmacy, Anhui Medical University, 81 Meishan Road, Hefei, Anhui 230032, People's Republic of China. ${ }^{3}$ Department of Pathology, Anhui Medical University, Hefei, Anhui, People's Republic of China.

\section{Authors' contributions}

WW, ZW, XM and CZ performed experiments; WW and JL designed research and wrote the paper; WW and ZW analyzed data. All authors read and approved the final Manuscript.

\section{Competing interests}

The authors declare that they have no competing interests.

Received: 5 July 2011 Accepted: 5 December 2011

Published: 5 December 2011

\section{References}

1. Grivennikov SI, Greten FR, Karin M: Immunity, inflammation, and cancer. Cell 2010, 140(6):883-899.

2. Grivennikov SI, Karin M: Inflammatory cytokines in cancer: tumour necrosis factor and interleukin 6 take the stage. Ann Rheum Dis 2011, 70(Suppl 1): 1104-i108.

3. Liu J, Yang G, Thompson-Lanza JA, Glassman A, Hayes K, Patterson A, Marquez RT, Auersperg N, Yu Y, Hahn WC, et al: A genetically defined model for human ovarian cancer. Cancer Res 2004, 64(5):1655-1663.

4. Saleh M, Trinchieri G: Innate immune mechanisms of colitis and colitisassociated colorectal cancer. Nat Rev 2011, 11(1):9-20.

5. Allen M, Louise Jones J: Jekyll and Hyde: the role of the microenvironment on the progression of cancer. J Pathol 2011, 223(2):162-176.

6. Mantovani A: Molecular pathways linking inflammation and cancer. Curr Mol Med 2010, 10(4):369-373.

7. Yu H, Pardoll D, Jove R: STATs in cancer inflammation and immunity: a leading role for STAT3. Nat Rev Cancer 2009, 9(11):798-809. 
8. Aggarwal BB, Kunnumakkara AB, Harikumar KB, Gupta SR, Tharakan ST, Koca C, Dey S, Sung B: Signal transducer and activator of transcription-3, inflammation, and cancer: how intimate is the relationship? Ann N Y Acad Sci 2009, 1171:59-76.

9. Karin M: NF-kappaB as a critical link between inflammation and cancer. Cold Spring Harb Perspect Biol 2009, 1(5):a000141.

10. $\mathrm{Yu} \mathrm{H}$, Kortylewski M, Pardoll D: Crosstalk between cancer and immune cells: role of STAT3 in the tumour microenvironment. Nat Rev 2007, 7(1):41-51.

11. Calvisi DF, Ladu S, Gorden A, Farina M, Conner EA, Lee JS, Factor VM, Thorgeirsson SS: Ubiquitous activation of Ras and Jak/Stat pathways in human HCC. Gastroenterol 2006, 130(4):1117-1128.

12. Rebouissou S, Amessou M, Couchy G, Poussin K, Imbeaud S, Pilati C, Izard T, Balabaud C, Bioulac-Sage P, Zucman-Rossi J: Frequent in-frame somatic deletions activate gp130 in inflammatory hepatocellular tumours. Nat 2009, 457(7226):200-204

13. Ferenci P, Fried M, Labrecque D, Bruix J, Sherman M, Omata M, Heathcote J, Piratsivuth T, Kew M, Otegbayo JA, et al: World Gastroenterology Organisation Guideline. Hepatocellular carcinoma (HCC): a global perspective. J Gastrointestin Liver Dis 2010, 19(3):311-317.

14. El-Serag HB, Rudolph KL: Hepatocellular carcinoma: epidemiology and molecular carcinogenesis. Gastroenterol 2007, 132(7):2557-2576.

15. Llovet JM, Bruix J: Molecular targeted therapies in hepatocellular carcinoma. Hepatology (Baltimore, Md) 2008, 48(4):1312-1327.

16. Asahina Y, Tsuchiya K, Tamaki N, Hirayama I, Tanaka T, Sato M, Yasui Y, Hosokawa T, Ueda K, Kuzuya T, et al: Effect of aging on risk for hepatocellular carcinoma in chronic hepatitis $C$ virus infection. Hepatology (Baltimore, Md) 2010, 52(2):518-527.

17. Gao B: Cytokines, STATs and liver disease. Cell Mol Immunol 2005, 2(2):92-100.

18. Radaeva S, Sun R, Pan HN, Hong F, Gao B: Interleukin 22 (IL-22) plays a protective role in T cell-mediated murine hepatitis: IL-22 is a survival factor for hepatocytes via STAT3 activation. Hepatol 2004, 39(5):1332-1342.

19. Naugler WE, Sakurai T, Kim S, Maeda S, Kim K, Elsharkawy AM, Karin M: Gender disparity in liver cancer due to sex differences in MyD88dependent IL-6 production. Science (New York, NY) 2007, 317(5834):121-124

20. Park $\mathrm{O}$, Wang $H$, Weng $H$, Feigenbaum L, Li H, Yin S, Ki SH, Yoo SH, Dooley S, Wang FS, et al: In vivo consequences of liver-specific interleukin-22 expression in mice: Implications for human liver disease progression. Hepatology (Baltimore, Md) 2011, 54(1):252-261.

21. Kusaba M, Nakao K, Goto T, Nishimura D, Kawashimo H, Shibata H, Motoyoshi Y, Taura N, Ichikawa T, Hamasaki K, et al: Abrogation of constitutive STAT3 activity sensitizes human hepatoma cells to TRAILmediated apoptosis. J Hepatol 2007, 47(4):546-555.

22. Lin L, Amin R, Gallicano Gl, Glasgow E, Jogunoori W, Jessup JM, Zasloff M, Marshall JL, Shetty K, Johnson L, et al: The STAT3 inhibitor NSC 74859 is effective in hepatocellular cancers with disrupted TGF-beta signaling. Oncogene 2009, 28(7):961-972.

23. Liu Y, Li PK, Li C, Lin J: Inhibition of STAT3 signaling blocks the antiapoptotic activity of IL-6 in human liver cancer cells. Biol Chem 2010, 285(35):27429-27439.

24. Hedvat M, Huszar D, Herrmann A, Gozgit JM, Schroeder A, Sheehy A, Buettner R, Proia D, Kowolik CM, Xin H, et al: The JAK2 inhibitor AZD1480 potently blocks Stat3 signaling and oncogenesis in solid tumors. Cancer cell 2009, 16(6):487-497.

25. Xin $H$, Zhang C, Herrmann A, Du Y, Figlin R, Yu H: Sunitinib inhibition of Stat3 induces renal cell carcinoma tumor cell apoptosis and reduces immunosuppressive cells. Cancer res 2009, 69(6):2506-2513.

26. Haftchenary S, Avadisian M, Gunning PT: Inhibiting aberrant Stat3 function with molecular therapeutics: a progress report. Anti-cancer drugs 2010.

27. $W Y W, Z S W, C L Z, X L M, P E L$ : Prognostic significance of phosphorylated signal transducer and activator of transcription 3 and suppressor of cytokine signaling 3 expression in hepatocellular carcinoma. Exp Ther Med 2011.

28. Vesselinovitch SD, Mihailovich N: Kinetics of diethylnitrosamine hepatocarcinogenesis in the infant mouse. Cancer Res 1983, 43(9):4253-4259.

29. Fan Y, Boivin GP, Knudsen ES, Nebert DW, Xia Y, Puga A: The aryl hydrocarbon receptor functions as a tumor suppressor of liver carcinogenesis. Cancer Res 2010, 70(1):212-220.
30. Levy DE, Darnell JE Jr: Stats: transcriptional control and biological impact. Nat Rev Mol Cell Biol 2002, 3(9):651-662.

31. Bollrath J, Phesse TJ, von Burstin VA, Putoczki T, Bennecke M, Bateman T, Nebelsiek T, Lundgren-May T, Canli O, Schwitalla S, et al: gp130-mediated Stat3 activation in enterocytes regulates cell survival and cell-cycle progression during colitis-associated tumorigenesis. Cancer cell 2009, 15(2):91-102.

32. Chan KS, Sano S, Kiguchi K, Anders J, Komazawa N, Takeda J, DiGiovanni J: Disruption of Stat3 reveals a critical role in both the initiation and the promotion stages of epithelial carcinogenesis. J Clin Invest 2004, 114(5):720-728.

33. Yang SF, Wang SN, Wu CF, Yeh YT, Chai CY, Chunag SC, Sheen MC, Lee KT: Altered p-STAT3 (tyr705) expression is associated with histological grading and intratumour microvessel density in hepatocellular carcinoma. J Clin Pathol 2007, 60(6):642-648.

34. He G, Yu GY, Temkin V, Ogata H, Kuntzen C, Sakurai T, Sieghart W, PeckRadosavljevic M, Leffert HL, Karin M: Hepatocyte IKKbeta/NF-kappaB inhibits tumor promotion and progression by preventing oxidative stress-driven STAT3 activation. Cancer cell 2010, 17(3):286-297.

35. Machida K, Tsukamoto H, Liu JC, Han YP, Govindarajan S, Lai MM, Akira S, $\mathrm{Ou} J \mathrm{H}$ : c-Jun mediates hepatitis $\mathrm{C}$ virus hepatocarcinogenesis through signal transducer and activator of transcription 3 and nitric oxidedependent impairment of oxidative DNA repair. Hepatology (Baltimore, Md) 2010, 52(2):480-492.

36. Park EJ, Lee JH, Yu GY, He G, Ali SR, Holzer RG, Osterreicher $\mathrm{CH}$ Takahashi H, Karin M: Dietary and genetic obesity promote liver inflammation and tumorigenesis by enhancing IL-6 and TNF expression. Cell 2010, 140(2):197-208.

37. Stolfi C, Rizzo A, Franze E, Rotondi A, Fantini MC, Sarra M, Caruso R, Monteleone I, Sileri $P$, Franceschilli $L$, et al: Involvement of interleukin-21 in the regulation of colitis-associated colon cancer. J Exp Med 2011.

38. Wang L, Yi T, Kortylewski M, Pardoll DM, Zeng D, Yu H: IL-17 can promote tumor growth through an IL-6-Stat3 signaling pathway. J Exp Med 2009, 206(7):1457-1464.

39. Starkel P, De Saeger C, Leclercq I, Strain A, Horsmans Y: Deficient Stat3 DNA-binding is associated with high Pias3 expression and a positive anti-apoptotic balance in human end-stage alcoholic and hepatitis $C$ cirrhosis. J Hepatol 2005, 43(4):687-695.

40. Starkel P, Saeger CD, Leclercq I, Horsmans Y: Role of signal transducer and activator of transcription 3 in liver fibrosis progression in chronic hepatitis C-infected patients. Lab Invest 2007, 87(2):173-181.

41. Culig Z: Cytokine disbalance in common human cancers. Biochimica et biophysica acta 2011, 1813(2):308-314.

42. Abiru S, Migita K, Maeda Y, Daikoku M, Ito M, Ohata K, Nagaoka S, Matsumoto T, Takii Y, Kusumoto K, et al: Serum cytokine and soluble cytokine receptor levels in patients with non-alcoholic steatohepatitis. Liver Int 2006, 26(1):39-45.

43. Bosch FX, Ribes J, Diaz M, Cleries R: Primary liver cancer: worldwide incidence and trends. Gastroenterol 2004, 127(5 Suppl 1):S5-S16.

44. Tang Y, Kitisin K, Jogunoori W, Li C, Deng CX, Mueller SC, Ressom HW, Rashid A, He AR, Mendelson JS, et al: Progenitor/stem cells give rise to liver cancer due to aberrant TGF-beta and IL-6 signaling. Proc Natl Acad Sci USA 2008, 105(7):2445-2450

45. Tebbutt NC, Giraud AS, Inglese M, Jenkins B, Waring P, Clay FJ, Malki S, Alderman BM, Grail D, Hollande F, et al: Reciprocal regulation of gastrointestinal homeostasis by SHP2 and STAT-mediated trefoil gene activation in gp130 mutant mice. Nat Med 2002, 8(10):1089-1097.

46. Pickert G, Neufert C, Leppkes M, Zheng Y, Wittkopf N, Warntjen M, Lehr HA, Hirth S, Weigmann B, Wirtz S, et al: STAT3 links IL-22 signaling in intestinal epithelial cells to mucosal wound healing. Exp Med 2009, 206(7):1465-1472.

47. Lee H, Deng J, Kujawski M, Yang C, Liu Y, Herrmann A, Kortylewski M, Horne D, Somlo G, Forman S, et al: STAT3-induced S1PR1 expression is crucial for persistent STAT3 activation in tumors. Nat Med 2010, 16(12):1421-1428.

48. Gao SP, Mark KG, Leslie K, Pao W, Motoi N, Gerald WL, Travis WD, Bornmann W, Veach D, Clarkson B, et al: Mutations in the EGFR kinase domain mediate STAT3 activation via IL-6 production in human lung adenocarcinomas. J Clin Invest 2007, 117(12):3846-3856.

49. Grivennikov S, Karin E, Terzic J, Mucida D, Yu GY, Vallabhapurapu S, Scheller J, Rose-John S, Cheroutre H, Eckmann L, et al: IL-6 and Stat3 are 
required for survival of intestinal epithelial cells and development of colitis-associated cancer. Cancer cell 2009, 15(2):103-113.

50. Kortylewski M, Kujawski M, Wang T, Wei S, Zhang S, Pilon-Thomas S, Niu G, Kay H, Mule J, Kerr WG, et al: Inhibiting Stat3 signaling in the hematopoietic system elicits multicomponent antitumor immunity. Nat Med 2005, 11(12):1314-1321.

51. Waldner MJ, Wirtz S, Jefremow A, Warntjen M, Neufert C, Atreya R, Becker C, Weigmann B, Vieth M, Rose-John S, et al: VEGF receptor signaling links inflammation and tumorigenesis in colitis-associated cancer. J Exp Med 2010.

52. Kujawski M, Kortylewski M, Lee H, Herrmann A, Kay H, Yu H: Stat3 mediates myeloid cell-dependent tumor angiogenesis in mice. J Clin Invest 2008, 118(10):3367-3377.

53. Niu G, Wright KL, Huang M, Song L, Haura E, Turkson J, Zhang S, Wang T, Sinibaldi D, Coppola D, et al: Constitutive Stat3 activity up-regulates VEGF expression and tumor angiogenesis. Oncogene 2002, 21(13):2000-2008.

54. Lafdil F, Wang H, Park O, Zhang W, Moritoki Y, Yin S, Fu XY, Gershwin ME, Lian ZX, Gao B: Myeloid STAT3 inhibits T cell-mediated hepatitis by regulating $\mathrm{T}$ helper 1 cytokine and interleukin-17 production. Gastroenterol 2009, 137(6):2125-2135, e2121-e2122.

\section{Pre-publication history}

The pre-publication history for this paper can be accessed here: http://www.biomedcentral.com/1471-2407/11/506/prepub

doi:10.1186/1471-2407-11-506

Cite this article as: Wu et al:: STAT3 activation in monocytes accelerates liver cancer progression. BMC Cancer 2011 11:506.

\section{Submit your next manuscript to BioMed Central} and take full advantage of:

- Convenient online submission

- Thorough peer review

- No space constraints or color figure charges

- Immediate publication on acceptance

- Inclusion in PubMed, CAS, Scopus and Google Scholar

- Research which is freely available for redistribution

Submit your manuscript at www.biomedcentral.com/submit 